\title{
Hidrelétrica de Belo Monte e o município de Altamira: processo de mudança social ou morfogênese?
}

\section{Hydrelectric plant of belo monte and the municipality of altamira: social change process or morphogenesis?}

Josep Pont Vidal - Doutor em Sociologia Política na Universidad de Barcelona (1997). Professor adjunto e pesquisador do Núcleo de Altos Estudos Amazônicos (UFPA). E-mail: vidalpont@yahoo.es

\section{Resumo}

A construção da mega Hidrelétrica de Belo Monte comporta impactos em toda a região do Xingu (estado do Pará). Este artigo descreve a primeira fase de observação realizada no município de Altamira durante o espaço temporal compreendido entre os anos de 2011 e 2013. Com base em uma perspectiva sociológica proveniente da teoria de sistemas sociais complexos. Nesta fase, são observadas as transformações que estão ocorrendo no sistema administrativo do município, assim como os primeiros resultados da observação das dinâmicas de mudança e diferenciação. Esta observação é feita em dois níveis. O primeiro focaliza as políticas públicas como formas comunicativas; o segundo, as estruturas que compõem o sistema político-administrativo.

\section{Palavras-chave}

Sistema político-administrativo. Políticas públicas. Hidrelétrica Belo Monte. Amazônia.

\begin{abstract}
The construction of the Belo Monte Hydroelectric Mega behavior impacts on the entire region of Xingu (Pará state). We describe the first phase of observation carried out in the town of Altamira in the temporal space between the years 2011 to 2013. Based on a sociological perspective from the theory of complex social systems, in this phase transformations in the administrative system of the municipality, as well as the first results and the observation of the dynamics of change and differentiation are observed. This is done in two levels. The first focused public policy as communicative forms, and second, the structures that make up the political-administrative system.
\end{abstract}

\section{Keywords}

Politic-administrative system. Governance. Hydroelectric of Belo Monte. Amazon. 


\section{A MUDANÇA SOCIAL}

A sociologia contemporânea surge de duas interpretações teóricas centrais. A primeira parte da ideia de que as sociedades têm uma estrutura imanente e autônoma quanto à vontade humana, sendo regida por leis próprias. A segunda parte do pressuposto de que as sociedades surgem como resultado de uma série de transformações históricas únicas, sendo, portanto, não repetíveis. Ambos pontos de vista teóricos focalizam duas questões centrais, o estudo da estrutura social e o estudo da mudança social. Neste trabalho, nos basearemos na análise da mudança social. A pergunta processo de mudança social ou morfogênese, formulada no título deste trabalho, indica a dificuldade de definir e determinar os processos de mudança social, visto transcorrerem longos períodos de tempo, em diferentes níveis ou esferas sociais e de diferentes formas e intensidades. Embora, obviamente, toda sociedade mude, não é tanto a qualidade e a profundidade da mudança ou se trata de um conjunto de pequenos ou de grandes mudanças e sua interconexão ou descontinuidade. Sua observação e análise dependerão da perspectiva teórico-metodológica que assume o observador, assim como da área do conhecimento que se toma como ponto de partida. Neste texto nos baseamos na orientação sociológica, especificamente na sociologia política e das organizações, ao aportar ambos os conceitos para a compreensão da mudança que observamos. Expomos e analisamos os resultados preliminares de uma ampla investigação, que tem como objetivo a observação do processo de mudança em diferentes níveis e esferas, e os impactos sociais que estão sendo produzidos na região do Xingu, no município de Altamira, como consequência da construção do megaprojeto hidrelétrico de Belo Monte.

O estudo da mudança social tem sido um dos mais analisados e também empiricamente observados desde as origens da sociologia por seus fundadores Durkheim, Spencer, Marx ${ }^{1}$. Já Eisenstadt indicava os problemas que comportam a observação da mudança social, indicando o papel da estrutura institucional como "viável, capaz de absorver uma mudança contínua" (EISENSTADT, 1970, p.12), conjuntamente com os movimentos sociais. A análise estrutural ou funcionalestrutural tem focalizado categorias como sistema, valores e manutenção de limites, limitando os problemas que aparecem com a observação da mudança. As novas perspectivas integradoras têm permitido a observação da mudança desde perspectivas mais dinâmicas, das quais têm surgido questões teóricas mais específicas para determinar a mudança em diferentes níveis: Quem ou que coisa

\footnotetext{
Para uma visão geral, ver REZENDE, Mario José de. Teorias da mudança social: as perspectivas lineares e as cíclicas. Revista de Ciências Humanas, n. 32, p. 349-378, 2002.
} 
produz a mudança social? (DONATI, 1992, p.31) Em que direção se produz? Trata-se de mudança apenas de caráter quantitativo, ou também qualitativo? O que é mudança? Os agentes e indutores da mudança podem ser sujeitos, grupos, associações, movimentos sociais ou as instituições governamentais. Trata-se de elementos interdependentes, dependendo do funcionamento de uma ação dos outros. Estas questões nos induzem a afirmar que toda teoria de mudança social é também uma teoria de conhecimento.

O conceito de mudança social está ligado hermeticamente às metateorias da mudança social, às teorias da transformação social, inclusive, às teorias do desenvolvimento, devido ao interesse científico para a compreensão da teoria da formação social, que, depois de alguns anos de letargia ${ }^{2}$, ganhou novos impulsos a partir de 1989 (KOLLMORGEN; SCHRADER, 2003; SZTOMPKA, 1993; DONATI, 1992). Com isso, mostrou-se que as teorias clássicas da mudança social não estavam de fora.

Outra linha de investigação de mudança social oferece o estudo das mudanças culturais. Este tipo de estudo focaliza o quanto as ações sociais coletivas coagem ou influenciam os membros (BAJOIT, 2008). Uma perspectiva vinculada com a administração pública provém da teoria das instituições. Com base na variável independente constituída pelas "instituições”, considerandoas a "manifestação mais significativa da mudança" (GÖHLER, 1996, p. 21), diversos estudos surgiram na década de 90 para observar as mudanças nos países (FEHR, 1994; MERKEL, 1995; SCHMALZ-BRUNS, 1989). É evidente que a importância institucional na mudança trata da teoria que focaliza a "transformação" de uma sociedade, não sendo esse caso nosso objeto de investigação. A maioria dos sociólogos concorda que a sociedade está constituída por comunicações, embora com diferentes pontos de partida (ação comunicativo de Habermas, 1981 e entendimento comunicativo de Luhmann, 1984). A ação político-administrativa do Estado se manifesta por meio de comunicações intersistêmicas. Neste sentido, a teoria de sistemas sociais complexo-autorreferenciais de Niklas Luhmann (1984; 1993; 1998) aporta um sofisticado e completo marco de referência conceitual.

As políticas públicas podem ser também indutoras da mudança social. $\mathrm{Na}$ análise estatística de políticas púbicas, o Estado, como ator principal, tem a responsabilidade do desenho das políticas públicas e sociais, visto ter um papel fundamental ao poder modular diferentes aspectos, tais como a cidadania, os destinatários dessas políticas e os serviços sociais, não incluídos nem na esfera

2 As questões relativas à mudança social têm sido formuladas por sociólogos como Wright Mills (1964), Germani (1964) e Eisenstadt (1992). 
doméstica nem no mercado (DYE, 2006; MENY; THOENIG, 1992). Pode também contribuir para a constituição de algumas linhas divisórias na estrutura social. A formação e a capacidade dos cidadãos para se organizar e se associar em entidades e realizar suas propostas de forma organizada têm uma repercussão direta nas diferentes esferas da ação. Surge inevitavelmente a questão: Que tipo de política pública propõe o poder público federal e municipal para a região?

O objetivo deste artigo é expor os resultados preliminares da observação de possíveis mudanças que têm sido produzidas basicamente no citado município, ou seja, no sistema político-administrativo local. Desde as ciências humanas e sociais, existem diversas formas de aproximação ao estudo da mudança. Uma possibilidade para a observação e a análise da mudança é oferecida pela análise das relações econômicas, produzidas em uma determinada região ou sociedade, mas a ausência de séries cronológicas de dados atualizados sobre as mudanças da estrutura econômica e social da região tem mostrado inviável este estudo. As fontes de dados mais recentes existentes datam do censo do IBGE realizado no ano de 2010, o que impossibilita uma observação durante o período de construção da UHBM. Com base nas premissas expostas, e desde a perspectiva de observação do sistema político-administrativo, formulam-se as seguintes hipóteses:

H1. Existe uma ampla proposta de políticas públicas e ações para a região, contudo a maioria delas não tem passado, ainda não passaram da fase do projeto, sendo, no melhor dos casos, lenta sua implementação. As ações implementadas correspondem mais a políticas assistencialistas e regulatórias dirigidas às instituições que a políticas distributivas ou de caráter emancipatório dirigidas à transformação da vida dos cidadãos e de suas famílias.

H2. O sistema político-administrativo municipal teve que reagir e se adaptar de forma reativa às demandas da esfera econômica, em especial às diretrizes marcadas e impostas pelo Consórcio Construtor Belo Monte (CCBM) e pela Norte Energia S.A. para as quais não estava preparado. Esta adaptação reativa tem tido consequências na estrutura do sistema (criação de nova secretaria), funções (relação com a esfera empresarial e governamental) e organização (planejamento e governança).

Contrastamos estas hipóteses com base na lógica de análise dos sistemas complexos ou autorreferentes (LUHMANN, 1984), os quais não se adaptam tampouco se orientam ao entorno, mas de forma estrutural, ou seja, em seu conjunto. O foco da observação se constitui em torno da ideia do sistema da administração pública municipal. No que concerne à administração pública municipal, referimo-nos ao conjunto de secretarias, organismos, autarquias e instituições vinculadas jurídica e economicamente ao organograma do poder 
público municipal. Diferenciamos a administração municipal da administração periférica, que é constituída pelo conjunto de órgãos e entidades públicas que exercem atividades administrativas, sistema que implica um conjunto identificável de estruturas com capacidade para criar suas próprias estruturas. Para um observador, um sistema é sistema "apenas se por meio de suas próprias operações o sistema se tornar autossistema" (LUHMANN, 1984:13). Com base na lógica de auto-observação do sistema administrativo municipal, a observação é feita em dois níveis. O primeiro é referente às comunicações entre o sistema administrativo municipal e o entorno, com base no código previamente estabelecido das políticas públicas. O segundo nível trata da auto-observação das estruturas que compõem o sistema, com base em códigos preestabelecidos e emergentes: 1) planejamento urbano; 2) tomada de decisões; 3) governança (Figura 1).

Figura 1 - Lógica da observação e conexões entre os códigos.

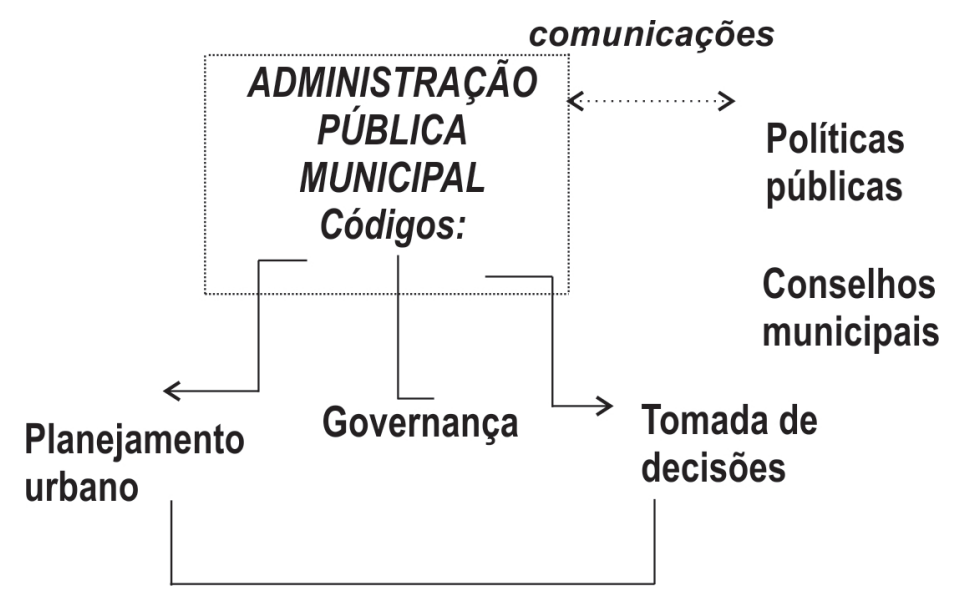

Fonte: Elaboração do autor.

Ao não assumir como variável independente as relações macroeconômicas, não entraremos no debate sobre o possível crescimento econômico que experimentará a região sob a ótica da construção da UHBM.

\section{MUDANÇA SOCIAL E MORFOGÊNESE NA TEORIA SOCIOLÓGICA}

Os mecanismos e componentes de mudança social têm sido observados e analisados sob diferentes paradigmas e "correntes". A sócio-história se refere às ideias como forças históricas (Weber) e à perspectiva histórica das grandes figuras como impulsoras das mudanças históricas (Thomas Carlyle). A corrente 
funcionalista referente às estruturas normativas (Durkheim, Merton) tem sido possivelmente a que mais tem proliferado. Sob uma visão do funcionalismo estrutural de Pitirim Sorokin (1937), o motor da mudança se encontra na "lógica interna de cada um dos sistemas", referindo-se aos sistemas político e cultural. A constatação da complexidade da mudança social deve ser entendida de forma dinâmica ao estabelecer uma "estreita relação entre as esferas social e cultural". Versões recentes da perspectiva neofuncionalista, como a variante cibernética de "esferas" (SEMASHKO, 2006), e a mais elaborada, constituída por sistemas autorreferenciais, são expressas pelo funcionalismo-estrutural de Luhmann (1984, 1992). Para este, a mudança social representa uma forma fundamental da diferenciação evolucionista e, em particular, uma forma de autossubstituição da identidade dos sistemas. Não menos importante têm sido as aportações do neomarxismo, que incidem no papel central dos atores e agentes sociais como indutores da mudança social, os movimentos sociais (Tilly; Tarrow; Klandermans, Offe), que, em sua variante ideológica, constituem as revoluções (James Davis, Ted Gurr, Theda Skockpol, Charles Tilly) ${ }^{3}$.

A perspectiva analítica sistêmica entende mudança social como "a mudança que acontece dentro do sistema social ou que o abarca [...] é a diferença entre os diversos estados do mesmo sistema ao se sucederem uns aos outros no tempo" (SZTOMPKA, 1995, p. 26). Em sua definição de mudança social, Hawley (1989, p. 787), citado em Sztompka (1995), p.27) reafirma o entendimento temporal e não recorrente não apenas de um aspecto da sociedade, mas de todo o sistema social: "Por mudança social, entendo uma alteração não recorrente de um sistema social considerado como um todo". O conceito implica, pois, três ideias centrais: diferença, em diferentes momentos temporais, entre estados do mesmo sistema. Implica também a transformação majoritária das relações e a "transformação" status na "estrutura ou estratificação social de uma sociedade". Em definitivo, trata-se da transformação das relações quantitativas e qualitativas em uma sociedade. A proposta de mudança social de Sztompka ressalta os processos sociais, os quais se manifestam de duas formas: o "desenvolvimento social"4 e

\footnotetext{
Entre as teorias da mudança, destacam-se: Boudon e Raymond. As teorias da mudança social; NISBET, ROBERT. Social Change and History. New York: Oxford University Press, 1969; LENSKI; GERHARD, History a Social Change. American Journal of Sociology, p. $548-564.1976$.

4 Como especificidades de "desenvolvimento social", podem-se entender o conceito de "desenvolvimento sustentável" e o de "desenvolvimento regional”. Sobre o primeiro, ver Standel e Garreta, (2011, p.39-57). Osvaldo Sunkel (2007, p. 23) estabelece a noção de desenvolvimento sustentável como uma vinculação com o desenvolvimento econômico e o meio ambiente. Relaciona os âmbitos do comportamento humano, evolução da natureza e conformação social do território.
} 
o "ciclo social". O primeiro denota como características a direcionalidade, que segue estados sempre superiores (crescentes diferenciação estrutural, econômica e tecnológica) e é estimulado de forma imanente (novas formas da vida social).

A noção de morfogênese tem origem biológica e pode ser definida como o processo pelo qual se vai desenvolvendo em um embrião os órgãos diferenciais de um adulto a partir de estruturas indiferenciadas, ou seja, o processo pelo qual um organismo adquire sua forma. O conceito de "morfogênese" tem sido utilizado em diferentes áreas do conhecimento e em diferentes tipos de investigação. Por um lado, na teoria cibernética das máquinas autômatas autorreprodutíveis e autoorganizativas (Foerster e von Neumann), a morfogênese vem sendo analisada desde uma perspectiva matemática. Por outro, desde o campo inicial da biologia (Maturana e Valera), no qual se tem transformado a noção de "morfogênese" em "autopoiese" e vinculando-a à "clausura organizativa". Uma terceira corrente (MAYURAMA, 1963) tem utilizado este conceito para compreender melhor os processos sociais. Um sistema que adota o beedback contrário ao de outro sistema com o qual está em comunicação. Como resultado, possibilita abranger processos evolutivos complexos.

No caso da observação do sistema administrativo municipal de Altamira, a criação de novas estruturas internas específicas e diferenciadas como consequência dos impactos da construção da UHBM corresponderia a um processo de "morfogênese". Em aportes posteriores, a noção de "morfogênese" tem derivado para as Teorias da Agência (Przeworski), segundo as quais ocorre a interação entre diversos indivíduos ou agentes que recebem instruções para executar, embora se limitem a um plano exclusivamente econômico. A ideia de "morfogênese social" como uma tentativa de enfocar a complexidade social desde uma perspectiva generativa, ou seja, a observação dos mecanismos que originam um fato ou uma ação se perfila por meio do conceito de "ruptura/recomposição de simetrias agenciais" (NAVARRO, 1995). Os grupos existem apenas por meio do conjunto de indivíduos que o integram, e que, por sua vez, encontram-se submetidos a processos de interação entre eles. Com base nesta premissa, é possível estabelecer duas dimensões: a microssocial e a macrossocial. A primeira ocorre no plano individual, do sujeito em interação com os outros sujeitos; e a macrossocial é constituída em um nível em que se expõem as consequências das decisões subjetivas. 


\section{METODOLOGIA DA OBSERVAÇÃO}

O sistema observado tem sido delimitado ao entorno dos nove municípios diretamente afetados pela construção da UHBM, que correspondem à delimitação feita pelo Plano de Desenvolvimento Regional Sustentável (PDRS). Observar o processo de mudança no sistema administrativo municipal implica a análise das mudanças específicas nas funções: governança, especialização, formas de planejamento e propostas de políticas públicas.

Para a observação dos sistemas autorreferenciais ou autopoiéticos, Luhmann estabelece uma diferença entre a observação elementar e a de segundo grau. Neste caso, referimo-nos a uma investigação de segundo grau, na qual alguma categoria tem emergido, segundo as informações dos entrevistados. As unidades de informação têm se constituído basicamente por entrevistas semiestruturadas com os representantes das secretarias municipais e dos conselhos. Nas entrevistas foram consideradas unidades de observação a tipologia, a qualidade e as formas de comunicação existentes.

Como técnicas de trabalho, foram utilizadas basicamente entrevistas semiestruturadas com os diversos atores e análise de conteúdo documental. Nessas entrevistas tem aparecido uma série de códigos emergentes não contemplados anteriormente (Quadro 1).

Quadro 1 - Técnicas utilizadas na observação do sistema administrativo municipal.

\begin{tabular}{|l|l|l|l|}
\hline $\begin{array}{c}\text { Sistema } \\
\text { político- } \\
\text { administrativo }\end{array}$ & \multicolumn{1}{|c|}{ Descrição } & Técnica & \multicolumn{1}{c|}{ Fontes } \\
\hline Nível federal & $\begin{array}{l}\text { Tipologia } \\
\text { de políticas } \\
\text { públicas e ações } \\
\text { governamentais } \\
\text { implementadas } \\
\text { na região }\end{array}$ & $\begin{array}{l}\text { Análise } \\
\text { documental }\end{array}$ & $\begin{array}{l}\text { - Operação Cidadania Xingu } \\
\text { - Operação Arco Verde" }\end{array}$ \\
\hline Nível estadual & $\begin{array}{l}\text { Tipologia } \\
\text { de políticas } \\
\text { públicas e ações } \\
\text { governamentais } \\
\text { implementadas } \\
\text { na região }\end{array}$ & Análise & documental \\
& $\begin{array}{l}\text { - Elano de Desenvolvimento } \\
\text { Regional Sustentável (PDRS) } \\
\text { - Secretaria de Comunicação } \\
\text { (Secom) } \\
\text { - Comitê Gestor do Plano de } \\
\text { Desenvolvimento Regional } \\
\text { Sustentável (PDRS) do Xingu }\end{array}$ \\
\hline
\end{tabular}




\begin{tabular}{|c|c|c|c|}
\hline $\begin{array}{l}\text { Nível } \\
\text { municipal }\end{array}$ & $\begin{array}{l}\text { Atores-chave da } \\
\text { administração } \\
\text { pública } \\
\text { municipal e } \\
\text { do "entorno } \\
\text { interno" }\end{array}$ & $\begin{array}{l}\text { Entrevistas } \\
\text { semiestrutu- } \\
\text { radas } \\
\text { Prefeitura de } \\
\text { Altamira }\end{array}$ & $\begin{array}{l}\text { - Secretário de Planejamento } \\
\text { de Altamira: Antonio Carlos } \\
\text { Bortoli (2008-2012), PSDB } \\
\text { - Vice-prefeito 2013: Joel } \\
\text { Mendes Oliveira. (governo } \\
\text { municipal) PMDB) } \\
\text { - Secretário de Planejamento } \\
\text { de Altamira, Raineiro Meireles } \\
\text { 2013. } \\
\text { - Secretário de Saúde de } \\
\text { Altamira } \\
\text { - Representante Governo em } \\
\text { Altamira }\end{array}$ \\
\hline
\end{tabular}

\section{A PESQUiSA: O MEGAPROJETO DA UHB E O MUNICÍPIO DE ALTAMIRA}

O projeto e a construção da Hidrelétrica de Belo Monte (a partir de agora UHB) têm desencadeado importantes mobilizações como resposta ao megaprojeto hidrelétrico que mudará a estrutura e a vida dos municípios afetados e da região ${ }^{5}$. Uma vez terminada a UHBM, com previsão para o ano de 2016, projeta-se inundar no mínimo $516 \mathrm{~km}^{2}$ (EIA, 2002; EIA-RIMA, 2008). No projeto inicial, mais de 2.000 famílias da periferia urbana de Altamira serão afetadas $^{6}$, sendo 800 na zona rural e cerca de 400 famílias ribeirinhas, totalizando aproximadamente 16.000 pessoas, além das populações indígenas. Informes de outros técnicos preveem que o número de afetados se eleve para 55\% ao alcançar 25.400 pessoas (Instituto Tecnológico/UFPA/MPF, 2012).

Em verde: alagamento cota 97 metros acima da altura do nível do mar. Em laranja: cota até 100 metros a ser atingida pelos efeitos da UHBM.

A este fato deve ser acrescentada a migração de trabalhadores barrageiros provenientes de outras regiões do país. Calcula-se, que alcançará cerca de 25.000 pessoas no pico da obra. Como em outros casos de fortes migrações de trabalhadores causadas pelos grandes projetos, uma vez concluída a obra, muitos deles provavelmente se instalarão com suas famílias na região. Com base

\footnotetext{
Municípios de Vitória do Xingu e Senador José Porfírio e, indiretamente, uma grande área que compreende os municípios de Brasil Novo, Medicilândia, Uruará, Placas, embora os impactos atinjam uma extensão maior.

6 Ver documento: Ministério Público Federal, Referência: ICP 1.23.003.000063/2007. Disponível em: <63.http://www.prpa.mpf.mp.br/news/2012/arquivos/ACP\%20Cota\%20100.pdf>
} 
nisso, especialistas identificaram graves problemas e sérias lacunas no estudo de impacto ambiental de Belo Monte?

Figura 1 - Alagamento do centro da cidade de Altamira: área a ser atingida pelos efeitos da UHE Belo Monte.

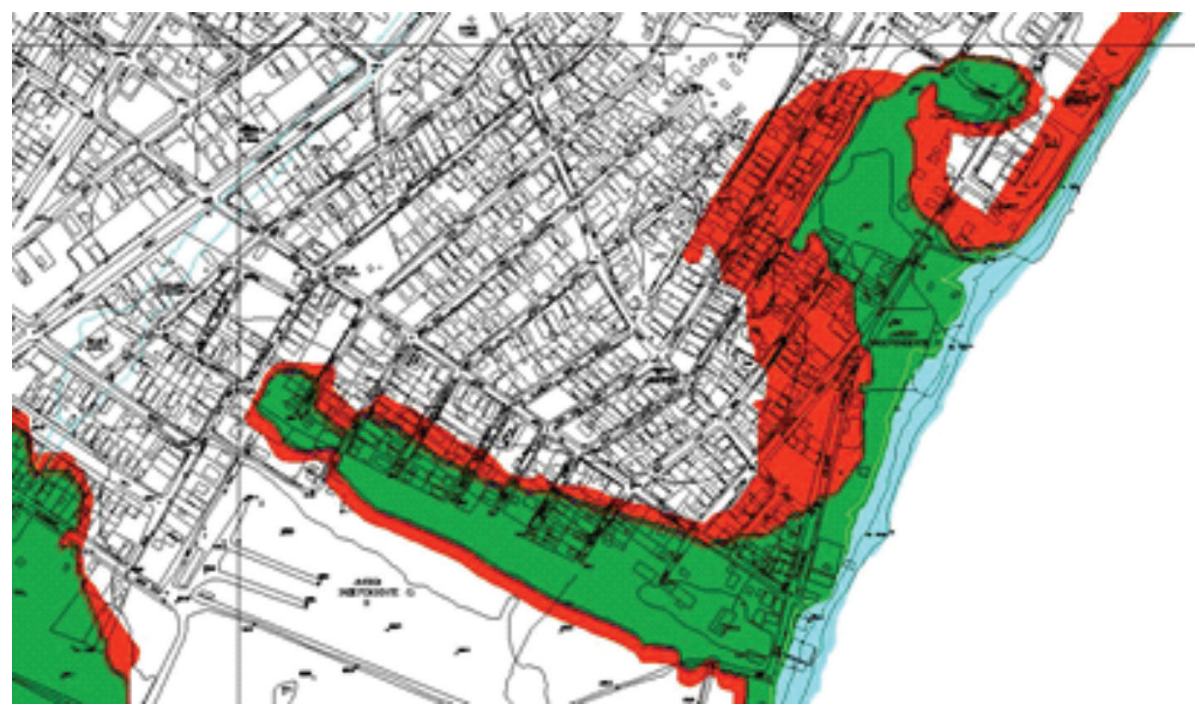

Fonte: Ministério Público Federal, Referência: ICP 1.23.003.000063/2007. Disponível em: <63.http://www.prpa.mpf.mp.br/news/2012/arquivos/ACP\%20Cota\%20100.pdf>

Este tipo de projeto desencadeará processos de crescimento, migrações e mudanças em todos os âmbitos, de forma quantitativa e qualitativa, na população, nas estruturas sociais e nas esferas econômica e administrativa da região ${ }^{8}$, de tal forma que se pode estabelecer um cenário antes e um depois da construção da UHBM. A construção de uma megainfraestrutura hidrelétrica deste tipo terá impactos profundos em toda a região do Xingu e na vida de seus habitantes, como tem ocorrido com a construção de outros megaprojetos na Amazônia. Um caso histórico similar ocorreu no sudeste do estado do Pará com a construção da UsinaHidrelétrica de Tucuruí.

\subsection{O Plano Desenvolvimento Sustentável e Hidrelétrica de Belo Monte}

O Plano do Desenvolvimento Sustentável (PDRS) faz parte de uma estratégia mais ampla promovida pelo Governo Federal, que toma como referência os

\footnotetext{
Magalhães e Hernandez (2009).

8 No texto, não entraremos na problemática da fragmentação do território e das regiões. Sobre este tema, consultar Haesbaert e Rogério (2007, p. 37-58).
} 
instrumentos de planificação federal, especialmente o Plano Amazônia Sustentável (PAS). Este Plano apoia-se na premissa de impulsionar um "novo modelo de desenvolvimento para a Amazônia a partir da valorização das potencialidades naturais e socioculturais". Para a realização deste plano, o governo do Pará subdividiu o estado em 12 regiões de integração, incluindo a Região Metropolitana de Belém, e que servem de apoio para a descentralização administrativa impulsionada pelo governo atual do Partido dos Trabalhadores (PT) no estado. A decisão governamental de iniciar PDRS na região do Xingu não é fortuita, mas está estreitamente vinculada à decisão governamental de iniciar as obras de construção da UHBM. O PDRS compreende uma série de ações estruturantes para a região, como os programas impulsionados pelo governo federal: o Plano Plurianual 2004-2007 (PPA), o projeto Territórios da Cidadania e o programa do governo do estado Pará Terra de Direitos, ambos integrados à Política Nacional de Desenvolvimento Regional (PNDR), e que compreendem ações conjuntas de diversos ministérios federais. Este Plano engloba uma série de ações em diversas escalas que determinam a ação das instituições e os respectivos papéis que exercem na esfera nacional, macrorregional, sub-regional e intraurbano.

\subsection{Atores e movimentos sociais na região do Xingu}

Vários autores e estudos indicam a existência de diversas tipologias de atores sociais tradicionais atuantes na região e nos municípios tais como comunidades indígenas, boiadeiros, empresas madeireiras, Igreja católica, igrejas evangélicas, sindicalismo rural, associações de pequenos agricultores, ONGs ecológicas, empresariado urbano local e os militares (Relatório do PDSBM, 2002). O Relatório do Plano inclui como atores mais importantes: "os grandes proprietários de terra, particularmente boiadeiros, as empresas madeireiras e o Movimento para o Desenvolvimento da Transamazônica e Xingu (MDTX)". A esses atores pode-se acrescentar a Fundação Viver, Preservar e Produzir (FVPP). Nesta pesquisa, centramo-nos na observação dos atores vinculados diretamente aos movimentos sociais surgidos em torno dos conflitos gerados pela construção da UHBM, e vinculados com ao Movimento Xingu Vivo para Sempre (MXVPS) (Quadro 2). O Movimento Pró-Belo Monte e Desenvolvimento Sustentável da região do Xingu não constitui o foco desta pesquisa e conceitualmente pode ser definido como um "contramovimento", ou seja, originalmente como um movimento para contrapor as ações e as mobilizações do MXVPS.

O programa se estende a 60 territórios por todo o país, participando 19 ministérios. 
Quadro 2 - Atores implicados no conflito da UHBM

\begin{tabular}{|c|c|}
\hline Ator & $\begin{array}{l}\text { Capacidade de mobilização na região do } \\
\text { Xingu }\end{array}$ \\
\hline $\begin{array}{l}\text { Agência Nacional de Energia Elétrica } \\
\text { (ANEL) }\end{array}$ & Realização de inventário Rio Xingu \\
\hline Universidades públicas & $\begin{array}{l}\text { Aprox. } 3.000 \text { estudantes, profesores e } \\
\text { funcionários }\end{array}$ \\
\hline $\begin{array}{l}\text { Secretaria do Meio Ambiente do Estado } \\
\text { do Pará (SEMA) }\end{array}$ & $\begin{array}{l}\text { Organiza audiências públicas sobre } \\
\text { empresas mineradoras na região }\end{array}$ \\
\hline Movimento MXVPS & $\begin{array}{l}\text { Aglutina aprox. } 140 \text { entidades locais } \\
(6 / 5 / 10)\end{array}$ \\
\hline $\begin{array}{l}\text { Fundação Viver Preservar Produzir } \\
\text { (FVPP) }\end{array}$ & $\begin{array}{l}\text { Coordena } 67 \text { organizações locais (2010), } \\
\text { "e uma média de } 200 \text { pessoas transitam } \\
\text { por base nessas organizações" } \\
\text { Outras fontes indicam a participação de } \\
113 \text { organizações nos } 12 \text { municípios do } \\
\text { sudeste do Pará (2007) }\end{array}$ \\
\hline $\begin{array}{l}\text { Federação dos Trabalhadores na } \\
\text { Agricultura do Estado do Pará } \\
\text { (FETAGRI) }\end{array}$ & 144 sindicatos afiliados (Pará) \\
\hline $\begin{array}{l}\text { Sindicato dos Educadores do Estado do } \\
\text { Pará (SINTEPP) }\end{array}$ & 600 afiliados na região do Xingu \\
\hline \begin{tabular}{|l|} 
Sindicato dos Trabalhadores. Rurais de \\
Altamira (STRA)
\end{tabular} & $\begin{array}{l}\text { 3.000-3.500 associados na região do } \\
\text { Xingu }\end{array}$ \\
\hline $\begin{array}{l}\text { Conferência Nacional dos Bispos do } \\
\text { Brasil (CNBB) } \\
\text { Conselho Indigenista Missionário (CIMI) }\end{array}$ & $\begin{array}{l}\text { Poder mediático e de mobilização social } \\
\text { Erwin Krautler, prêmio Right Livelihood, } \\
\text { em defesa dos índios. }\end{array}$ \\
\hline Igrejas cristãs, Pastoral da Terra & Poder de mobilização social \\
\hline $\begin{array}{l}\text { Instituto Brasileiro do Meio Ambiente } \\
\text { e dos Recursos Naturais Renováveis } \\
\text { (IBAMA) }\end{array}$ & $\begin{array}{l}\text { Autarquia federal que emite Estudos } \\
\text { de Impacto Ambiental (EIA) para a } \\
\text { construção da UHE }\end{array}$ \\
\hline $\begin{array}{l}\text { Fundação Nacional do Índio (FUNAI) } \\
\text { Finalidade: "proteger e promover os } \\
\text { direitos dos povos indígenas, em nome da } \\
\text { União" }\end{array}$ & $\begin{array}{l}\text { Autarquia federal. Afetados diretamente: } \\
7 \text { etnias indígenas com } 1.690 \text { pessoas }\end{array}$ \\
\hline $\begin{array}{l}\text { Instituto Nacional de Colonização e } \\
\text { Reforma Agrária (INCRA) }\end{array}$ & \begin{tabular}{|l} 
Autarquia federal com o objetivo de \\
gerenciar a distribuição de terras
\end{tabular} \\
\hline Movimento Indígena & $\begin{array}{l}10 \text { etnias afetadas indiretamente: } \\
\text { Kayapó, Paquiçamba, Apyterewa, Arara, } \\
\text { Jacareacanga, Mundurucus. }\end{array}$ \\
\hline
\end{tabular}




\begin{tabular}{|l|l|}
\hline Movimento de Mulheres & $\begin{array}{l}\text { Aglutina pequenos movimentos locais de } \\
\text { mulheres. Poder de mobilização: médio }\end{array}$ \\
\hline Movimento: MFX & $\begin{array}{l}\text { Aglutina aproxidamente } 170 \text { entidades } \\
\text { locais }(6 / 5 / 10)\end{array}$ \\
\hline $\begin{array}{l}\text { Associação Comercial, Industrial e } \\
\text { Agropastoril de Altamira (ACIAPA) }\end{array}$ & 159 atores associados \\
\hline $\begin{array}{l}\text { Associação dos Municípios das Rodovias } \\
\text { Transamazônica, Santarem-Cuiabá e }\end{array}$ & $\begin{array}{l}\text { Representação dos municípios: Almeirim, } \\
\text { Altamira, Anapu, Aveiro, Belterra, } \\
\text { Brasil Novo, Itaituba, Jacareacanga, } \\
\text { Medicilândia, Novo Progresso, Novo } \\
\text { Repartimento, Pacajá, Placas, Porto de } \\
\text { Moz, Rurópolis, Santarém, Senador José } \\
\text { Porfírio, Trairão, Uruará, Vitória do } \\
\text { Xingu. }\end{array}$ \\
\hline Conselho Gestor PDRS Xingu & $\begin{array}{l}30 \text { representantes de entidades + 30 } \\
\text { suplentes }\end{array}$ \\
\hline
\end{tabular}

Fonte: Elaboração do autor.

Os atores da sociedade civil estão vinculados a diversos movimentos sociais, entre os quais destacamos:

- Movimento Xingu Vivo para Sempre. As origens deste movimento remontam a meados da década de 1980, a partir do "I Encontro dos Povos Indígenas" (Altamira), e com a primeira proposta de construção da hidrelétrica. Desde então, o movimento teve fases de mobilização, dependendo dos projetos e da retomada de construção da usina hidrelétrica. O momento atual de revitalização do movimento remonta a princípios de 2008, por ocasião do encontro "Xingu Vivo para Sempre", com representantes das populações indígenas, ribeirinhas e extrativistas; dos agricultores familiares, dos moradores da cidade de Altamira, dos movimentos sociais e das Organizações Não Governamentais da foz do rio Xingu, para discutir e avaliar o projeto de construção da hidrelétrica. Este movimento é formado por 60 entidades e associações da sociedade civil.

- O Movimento de Mulheres. Surge em princípios da década de 1990. Compõe-se do Movimento de Mulheres Trabalhadoras de Altamira Campo Cidade (MMTACC), Movimento de Mulheres Maria Maria (MMM), Instituto Feminista para a Democracia e do Fórum de Mulheres da Amazônia Paraense. 
- Movimento dos Trabalhadores Rurais sem Terra (MST). Representa um amplo movimento de cunho nacional, com importante atuação em mobilizações no Pará. Este Movimento está vinculado a outros movimentos sociais, como o Movimento Nacional pelos Direitos Humanos (MNDH).

\section{- Movimento Pró-Belo Monte e Desenvolvimento Sustentável da Região do Xingu.} Surge a partir do movimento contra a construção da UHBM, tratando-se, pois, de um "contramovimento". O movimento tem na coordenação o Comitê Pró-Belo Monte, composto por 170 entidades. Desde a sua criação realizaram-se diversas manifestações e ações. Entre as reivindicações está a retomada dos estudos de impacto para a construção da hidrelétrica, a elaboração de uma política para o setor florestal, o asfaltamento das estradas federais, a conservação das estradas vicinais, o zoneamento socioeconômico e a regularização fundiária.

- Movimento Indígena. Este movimento não foi estudado mais atentamente, pois excede os objetivos desta pesquisa, e requer estudos específicos de antropologia. Desde as suas origens, nos protestos também participam os grupos formados por indígenas. Estes desenvolveram uma estrutura própria, de tal forma que se configura como um movimento praticamente autônomo durante os ciclos de protestos do MXVPS. Este movimento está integrado a diversos grupos, como os Kayapó, Paquiçamba, Apyterewa, Arara, Jacareacanga e Mundurucu. Neste movimento também atuam diversas associações, como a Associação dos Povos Indígena do Xingu.

Com relação às redes, na região existem inúmeras redes informas instituídas por comunidades locais e ribeirinhas. Estas redes, pela sua natureza informal, são difíceis de mapear ou delimitar, visto que seria necessário realizar um estudo específico de caráter antropológico ou sociológico. No entanto, constata-se a existência das seguintes redes informais: Grupo Trabalho Amazônico (GTA), Fórum da Amazônia Oriental (FAOR) e RECEPARA, esta última de caráter educativo ${ }^{10}$.

\subsection{Dinâmicas na região do Xingu antes de 2011}

O processo institucional na região amazônica se caracteriza pelo baixo nível de institucionalidade ou "frágil institucionalidade" (TORRES, 2004, p. 45),

10 A maioria de Organizações Não Governamentais da região faz parte de redes nacionais como o Fórum Brasileiro de ONGs e os Movimentos Sociais para o Meio Ambiente e o Desenvolvimento (FBOMS). 
aparecendo em maior ou menor intensidade seja em áreas urbanas ou rurais, no grau de racionalidade, no poder e na execução de políticas. Historicamente, o Estado brasileiro tem se caracterizado pela sua ausência nas políticas públicas para a região, criando tão somente instituições de orientação desenvolvimentista que permitiam a gestão burocrática a partir de outros centros do país, correspondendo a um conjunto de agentes sociais e a interesses relativamente "alheios aos interesses sociais da Amazônia" (CASTRO; HEBETTE, 1989; CASTRO; MOURA; SÁ MARIA, 1995; BECKER, 2005).

Os processos de mobilização da sociedade civil iniciaram no final da década de 1970 do século passado, com a construção da BR-230 (Rodovia Transamazônica) e os primeiros projetos de implantação de hidrelétricas no rio Xingu analisados e detalhados (MDTX, 2001; PINTO, 1996). Especificamente, as dinâmicas político-administrativas também têm sido objeto de diversos estudos. O estudo de Hoefle (2003), embora embasado em uma observação no estado do Amazonas, expõe uma série de declarações que podem expressar a realidade do estado do Pará: "Muitos políticos também são funcionários federais e estaduais que continuam recebendo seus salários enquanto estão de licença para exercer cargo público, ampliando ainda mais a disparidade social entre a classe política e a população local subempregada" (HOEFLE, 2003). No passado, os comerciantes de ambas as cidades eram intermediários importantes na exportação de produtos da floresta, mas depois do seu processamento inicial, e não apenas de sua exportação in natura.

Consequentemente, seus líderes políticos sempre tiveram uma base de poder diversificada que hoje inclui fábricas, supermercados, cinemas e postos de gasolina. Quando um prefeito eleito é funcionário público ou empregado de uma companhia privada, esta pessoa invariavelmente representa aqueles interesses (HOEFLE, 2003).

$\mathrm{Na}$ perspectiva institucional, sobressai uma série de características nesta área periférica, como a existência de redes formais e informais de associações na região. Como consequência, têm surgido reivindicações históricas à margem dos canais tradicionais de participação, orientadas para o desenvolvimento da região. A isso também deve ser acrescentada a presença de populações autóctones que vêm tendo suas formas de subsistência e de vida ameaçadas, como é o caso dos grupos indígenas ${ }^{11}$.

11 Para informação sobre os diferentes grupos indígenas na região, ver: Plano Territorial de Desenvolvimento Rural Sustentável (PTDRS). 2010. FVPP-SOMEC-Ministério de Desenvolvimento, Altamira, 2010. Disponível em: <http://sit.mda.gov.br/download/ptdrs/ ptdrs_qua_territorio095.pdf> Acesso: 20 jan. 2013. 


\subsection{Governo estadual, municípios e políticas públicas}

O impacto direto e indireto da construção da UHB compreende um total de seis municípios na região do Xingu. O orçamento municipal constitui um elemento básico para a configuração de políticas, serviços e estruturas urbanas para o município. Aparecem algumas tendências determinantes para a compreensão das políticas públicas e ações municipais. Neste sentido, cabe destacar o vertiginoso aumento do orçamento do município de Vitória do Xingu, ao passar de algo em torno de $\mathrm{R} \$ 12$ milhões no ano de 2009 a quase $\mathrm{R} \$ 100$ milhões três anos mais tarde. Uma tendência similar se manifesta no município de Altamira. Ambos os municípios são os que mais sofreram o impacto da construção da UHBM. Nos outros municípios, há um incremento mais moderado dos recursos, com aumento em torno de 40\% (Tabela 1).

Tabela 1 - Orçamento dos municípios observados (2007-2012)

\begin{tabular}{l|l|l|l|l|l|l}
\hline & 2007 & 2008 & 2009 & 2010 & 2011 & 2012 \\
\hline Altamira & $83.661 .522,40$ & $97.563 .557,00$ & $97.780 .348,00$ & $108.056 .637,00$ & $143.369 .814,00$ & $179.085 .122,73$ \\
\hline $\begin{array}{l}\text { Vitória do } \\
\text { Xingu }\end{array}$ & Não informa & Não informa & $12.245 .489,00$ & $16.645 .482,00$ & $39.986 .182,69$ & $97.269 .639,38$ \\
\hline $\begin{array}{l}\text { Senador José } \\
\text { Porfírio }\end{array}$ & $11.993 .666,72$ & $14.959 .009,00$ & $15.711 .280,00$ & $18.086 .281,00$ & $23.170 .864,00$ & Não informado \\
\hline Brasil Novo & $14.656 .230,00$ & $18.139 .107,00$ & $19.005 .250,00$ & $22.137 .694,00$ & $26.286 .332,63$ & Não informado \\
\hline Medicilândia & $20.945 .550,49$ & $27.334 .039,93$ & $22.334 .472,94$ & $28.944 .080,27$ & $34.457 .206,38$ & Não informado \\
\hline Uruará & $30.199 .615,26$ & $36.629 .887,75$ & $36.586 .567,30$ & $46.638 .920,85$ & $52.700 .157,13$ & Não informado \\
\hline Placas & Não informa & Não informa & $15.408 .655,73$ & $18.571 .812,36$ & $25.410 .047,39$ & Não informado \\
\hline
\end{tabular}

Fonte: DATASUS; Leila Márcia. Disponível em: http://portalsaude.saude.gov.br/ portalsaude/texto/7056/908/Dados-Informados.html

A estratégia do governo do estado do Pará tem sido centrada no Plano de Desenvolvimento Regional Sustentável (PDRS) ${ }^{12}$. O objetivo é promover políticas públicas para a melhoria da qualidade de vida da população que habita a área de abrangência do Plano, sendo que as consultas públicas têm constituído o eixo propositivo. Nessas consultas foram expostas e discutidas as políticas públicas e as ações do governo. Contudo, não se entrou no debate da construção da UHBM, fato que tem sido apontado como indiscutível e, portanto, não incluído na pauta e na agenda das consultas públicas.

A construção da UHBM afeta diretamente as comunidades indígenas, e mesmo áreas do Parque Indígena do Xingu ${ }^{13}$. Desde o início das reuniões no ano 2007, a UHBM tem procurado oferecer uma imagem idílica e livre de conflitos

12 PDRS instituído em 2010, por meio do Decreto n 7.340 .

13 Parque Indígena do Xingu, fundado em 1961, como uma referência no Brasil. É habitado por 16 povos indígenas diferentes, além de ser uma ilha de sociobiodiversidade. 
entre a empresa Norte Energia e as comunidades indígenas da região, - as mais afetadas. No documento informativo da empresa ${ }^{14}$, ela expõe a forma como o governo brasileiro vinculou as populações indígenas ao planejamento do projeto de Belo Monte, especificamente com a participação da Fundação Nacional do Índio (FUNAI):

[...] realizou mais de 30 reuniões entre 2007 e 2010, com a participação de cerca de 1.700 indígenas em aldeias locais [...]. Muitos líderes indígenas também estiveram ativamente envolvidos em reuniões públicas realizadas durante a elaboração do Estudo de Impacto Ambiental (EIA).

No ano de 2011, a Secom do governo do Pará15 publicou: "Estado amplia presença na região do Xingu com Plano de Desenvolvimento, Casa de Governo e Operação Cidadania". Com isso, propunha-se a fomentar um desenvolvimento sustentável com base em um consenso multinível entre os governos:

Além da regularização fundiária, uma série de ações buscará fomentar o desenvolvimento sustentável, mitigar os impactos da construção da usina e potencializar os efeitos positivos do empreendimento.

Os encontros na cidade de Altamira tiveram como objetivo "materializar as iniciativas estatais, efetivar o diálogo interinstitucional e monitorar a implementação do Plano de Desenvolvimento Regional Sustentável (PDRS) do Xingu, que foi elaborado numa parceria entre cerca de 40 órgãos federais" "16. O PDRS do Xingu está constituído por cinco eixos temáticos, em um conjunto de 287 ações do governo ${ }^{17}$. O objetivo do Plano é

[...] complementar as exigências do processo de licenciamento ambiental, unindo políticas públicas dos três níveis de governo para a capacitação de mão de obra, ampliação de escolas e universidades [...]. Outros objetivos são incentivar as atividades econômicas com ordenamento fundiário e investimentos em infraestrutura.

Entre as medidas a serem implementadas em carater de urgência, o Governo Federal propôs uma série de ações simultâneas para o desenvolvimento sustentável da região ${ }^{18}$. A Secom publicou o valor dos investimentos de

14 UHE Belo Monte. Perguntas e respostas. Secretaria de Comunicação Social/PR p. 4. Disponível em: <http://www.brasil.gov.br/sobre/economia/energia/obras-e-projetos/belomonte-1> Acesso em: 3 maio 2013.

15 Secom, 2 jun. 2011.

16 Ibid. 2011.

17 Disponível en: <http://www.mi.gov.br/c/document_library/get_file?uuid=9cbd2d8c-9e8c4db0-a362-f7f4af1e9b96\&groupId=24915> Acceso em: 10 dez. 2012.

18 Entre as ações: 1) a implantação do Comitê Gestor do Plano de Desenvolvimento Regional Sustentável (PDRS) do Xingu; 2) a criação da Casa do Governo Federal; e 3) o início da Operação Cidadania Xingu. O objetivo destas ações é promover o desenvolvimento sustentável da região do Xingu. 
R \$ 3,2 bilhões, que se destinam à “construção e ampliação de escolas, postos de saúde, apoio à segurança pública, saneamento e habitação, entre outras, sob a responsabilidade da empresa vencedora do leilão, responsável pela implantação do empreendimento" "19. Inevitavelmente, surge a pergunta: Estas promessas estão sendo cumpridas? Como propostas de ações e políticas públicas, cabe mencionar: a criação do Comitê Gestor do Plano de Desenvolvimento Regional Sustentável (PDRS) do Xingu em Altamira e a "Operação Cidadania Xingu”.

O comitê é formado por representantes dos governos federal, estadual e municipal, comunidades indígenas, movimentos sociais, organizações ambientais, entidades sindicais dos trabalhadores rurais, urbanos, de pescadores e entidades patronais. O PDRS surge da parceria entre o Governo Federal e o Governo do Estado do Pará e constitui-se em um dos instrumentos para a descentralização das políticas públicas: “tem sido objeto da implementação de planos de desenvolvimento com base nas potencialidades locais, por meio do Planejamento Territorial Participativo (PTP)" ${ }^{\prime 20}$.

O PDRS do Xingu vem se somar a outros planos de desenvolvimento regionais sustentáveis elaborados no país, em particular na Amazônia, referenciados no Plano Amazônia Sustentável (PAS), que formulou e vem desenvolvendo um novo modelo de desenvolvimento para a Amazônia Legal. A elaboração do PDRS esteve a cargo de um Grupo de Trabalho Intergovernamental (GTI), com base na metodologia do Planejamento Territorial Participativo (PTP).

\subsection{A “Operação Cidadania Xingu”}

A "Operação Cidadania Xingu" é uma parceria entre mais de 30 instituições das três esferas do governo, com o objetivo de levar políticas e ações que promovam o desenvolvimento sustentável da região, com foco na melhoria da qualidade de vida da população rural e urbana dos municípios que serão impactados pela construção da UHBM. Esta ação foi realizada em Altamira com representantes das três esferas de governo e de representantes da sociedade civil. Foram discutidos temas prioritários para o desenvolvimento sustentável do município, "como a pavimentação da BR Transamazônica, regularização fundiária, saúde, educação e saúde pública" ${ }^{21}$. Foram programadas reuniões nos 11 municípios da área de abrangência da usina de Belo Monte. Em cada encontro é definida uma agenda de compromissos com ações imediatas, que serão disponibilizadas para a população durante o "Mutirão Cidadania Xingu".

\footnotetext{
Secom, 2 jun., 2011.

Secom, 22 jul., 2011.

$21 \quad$ Secom, 21 jul., 2011.
} 
Da primeira reunião participaram representantes das três esferas de governo, juntamente com a sociedade civil, sendo discutidos temas mais urgentes, tais como: desenvolvimento sustentável do município, pavimentação da BR-230 (Transamazônica), regularização fundiária, saúde, educação e saúde pública. Em agosto de 2011 foi iniciado o primeiro "mutirão", quando foram realizados seminários, palestras e prestação de serviços (fornecimento de carteira de identidade, CPF e Carteira de Trabalho), para "fazer um primeiro contato com a população" e para "implantar as políticas públicas, pois temos que vencer o problema do sub-registro, que, nessa região, é muito grande" 22 . Um dos principais problemas foi que uma parte significativa da população não dispunha de documentos (carteira de identidade e CPF), "ficando impossível chegar com as políticas públicas"”23, como no caso do Programa Bolsa Família, por exemplo (Quadros 3 e 4).

Quadro 3 - Ações e políticas urgentes do governo federal

\begin{tabular}{|c|c|c|c|}
\hline Programas & Atores/Ações & Orçamento & $\begin{array}{l}\text { Tipologia } \\
\text { da política }\end{array}$ \\
\hline PAC-2 & $\begin{array}{l}\text { Entrega de máquinas retroescavadeiras } \\
\text { a prefeituras de cidades com menos de } \\
50.000 \text { habitantes. } \\
\text { - Pavimentação de parte da } \\
\text { Transamazônica. }\end{array}$ & & $\begin{array}{l}\text { Redistri- } \\
\text { butiva em } \\
\text { nível muni- } \\
\text { cipal }\end{array}$ \\
\hline $\begin{array}{l}\text { Operação } \\
\text { Arco de } \\
\text { Fogo }\end{array}$ & $\begin{array}{l}\text { Visa a combater o desmatamento ilegal na } \\
\text { Amazônia por meio de ações de segurança } \\
\text { pública promovidas pelas Polícias Federal, } \\
\text { Civil e Militar e órgãos das três instâncias } \\
\text { governamentais. }\end{array}$ & $\begin{array}{l}\text { Dados não } \\
\text { disponibili- } \\
\text { zados pelo } \\
\text { Estado }\end{array}$ & Regulatória \\
\hline $\begin{array}{l}\text { Operação } \\
\text { Arco Verde- } \\
\text { Terra Legal }\end{array}$ & $\begin{array}{l}\text { Tem como proposta desenvolver nas } \\
\text { populações locais novos modelos de } \\
\text { exploração econômica, invertendo a lógica } \\
\text { do desmatamento. } \\
\text { Realizada nos } 43 \text { municípios com maior } \\
\text { índice de desmatamento na Amazônia em } \\
2009 \text {. }\end{array}$ & $\begin{array}{l}\text { Dados não } \\
\text { disponibili- } \\
\text { zados pelo } \\
\text { Estado }\end{array}$ & Regulatória \\
\hline
\end{tabular}

22 A região se caracteriza pelo baixo registro de cidadãos. Disponível em: < http://culturadigital. $\mathrm{br} /$ cidadaniaxingu/>

23 Ibid. id. 


\begin{tabular}{|l|l|l|l|}
\hline Estratégia & REDD+ (Redução de Emissões de & & Regulatória \\
Nacional de & Desmatamento e Degradação Florestal) & & \\
& $\begin{array}{l}\text { é um conjunto de políticas e incentivos } \\
\text { positivos para a redução das emissões } \\
\text { provenientes de desmatamento e } \\
\text { degradação florestal, e incremento de } \\
\text { estoques de carbono florestal (incluindo } \\
\text { conservação e manejo florestal } \\
\text { sustentável). Por meio de consultas, } \\
\text { estabelece-se um acordo entre os } \\
\text { municípios da região para a concepção } \\
\text { de um modelo de desenvolvimento rural } \\
\text { sustentável com base na redução do } \\
\text { desmatamento e das queimadas. }\end{array}$ & & \\
\hline
\end{tabular}

Fonte: Elaboração do autor com base em informações da Secom.

A criação e o funcionamento dos Conselhos estão regulados por Lei. Os conselhos dispõem de autonomia nas tomadas de decisão e o seu funcionamento é na forma de colegiado. As decisões são tomadas com base "no regimento do Conselho". A relação dos conselhos com o poder municipal é complexa. "No conselho tutelar, a gente faz tudo para não aceitar 'a política'. A política 'não interfere aqui'" (Coordenadora do Conselho Tutelar). 
Quadro 4 - Políticas públicas urgentes e ações (até outubro 2013).

\begin{tabular}{|c|c|c|c|c|}
\hline $\begin{array}{l}\text { Ator/ } \\
\text { Ação }\end{array}$ & Objetivos e ações & $\begin{array}{l}\text { Orçamento } \\
\text { (1) }\end{array}$ & $\begin{array}{c}\text { Destina- } \\
\text { tários } \\
\text { Policy-takers }\end{array}$ & $\begin{array}{l}\text { Tipologia } \\
\text { (Secchi, } \\
2020)\end{array}$ \\
\hline $\begin{array}{l}\text { Governo } \\
\text { federal: Acordo } \\
\text { de cooperação: } \\
\text { Ibama - Norte } \\
\text { Energia }\end{array}$ & $\begin{array}{l}\text { Apoio logístico às ações para controlar os } \\
\text { crimes ambientais, como o tráfico de animais } \\
\text { silvestres e a exploração ilegal de madeira. } \\
\text { Além de investimento em infraestrutura, em- } \\
\text { presa financiará a proteção da floresta e das } \\
\text { terras indígenas. }\end{array}$ & $\begin{array}{l}\mathrm{R} \$ 3,2 \\
\text { bilhões } \\
\text { Não espe- } \\
\text { cíifica a área } \\
\text { de abran- } \\
\text { gência }\end{array}$ & $\begin{array}{l}\text { Polícias } \\
\text { federal e } \\
\text { estadual }\end{array}$ & $\begin{array}{l}\text { Regulatória } \\
\text { constitu- } \\
\text { tiva }\end{array}$ \\
\hline $\begin{array}{l}\text { Governo } \\
\text { federal: } \\
\text { Norte Energia } \\
\text { Termos de } \\
\text { Compromisso } \\
\text { entre a Nesa, } \\
\text { prefeituras e } \\
\text { governo do } \\
\text { estado do Pará }\end{array}$ & $\begin{array}{l}\text { Fortalecimento da segurança pública para aten- } \\
\text { der o potencial aumento da população. }\end{array}$ & $\begin{array}{l}\mathrm{R} \$ 100 \\
\text { milhões }\end{array}$ & & Regulatória \\
\hline $\begin{array}{l}\text { "Operação Ci- } \\
\text { dadania Xingu" }\end{array}$ & $\begin{array}{l}\text { - Mesmos moldes do mutirão "Arco Verde - } \\
\text { Terra Legal", realizado nos } 43 \text { municípios com } \\
\text { maior índice de desmatamento na Amazônia } \\
\text { em } 2009 \text {. } \\
\text { - Atendendo mais de oito mil famílias; recursos } \\
\text { para mais de } 21 \text { mil famílias assentadas adqui- } \\
\text { rirem materiais para construção ou reforma de } \\
\text { casas. } \\
\text { - Emissão de títulos definitivos para mais de } \\
\text { cinco mil famílias assentadas e aumento da as- } \\
\text { sistência técnica a famílias assentadas. } \\
\text { - Instalação de agências bancárias do Banco do } \\
\text { Brasil; aumento de } 43 \% \text { no apoio à comercia- } \\
\text { lização dos produtos da Agricultura Familiar. } \\
\text { - } 7.425 \text { cadastramentos realizados no programa } \\
\text { Terra Legal e } 1,43 \text { milhões de hectares cadas- } \\
\text { trados; } \\
\text { - } 175.200 \text { atendimentos aos cidadãos de } 11 \\
\text { municípios } \\
\text { - Entrega de } 43 \text { minibibliotecas. } \\
\text { - Doação de } 129 \text { Arcas das Letras. } \\
\text { - Crição do Programa Nacional de Fortaleci- } \\
\text { mento da Agricultura Familiar (Pronaf) Susten- } \\
\text { tável. } \\
\text { - Programa Terra Legal Amazônia. Cadastro de } \\
1.513 \text { ocupantes de terras federais na região. O } \\
\text { programa está digitalizando o acervo fundiário } \\
\text { do Instituto Nacional de Colonização e Refor- } \\
\text { ma Agrária (Incra) } \\
\text { - Oferecimento de cursos de capacitação sobre } \\
\text { sistema de cooperativismo e produção susten- } \\
\text { tável, sistemas agroflorestais e de aquicultura e } \\
\text { pesca (Embrapa) } \\
\text { Identificação de } 21.291 \text { famílias aptas a partici- } \\
\text { par do programa Luz para Todos. } \\
\text { - Universidade Federal do Pará: início do curso } \\
\text { de medicina (inicial: R } \$ 2 \text { milhões; final: R } \$ 20 \\
\text { milhões). }\end{array}$ & 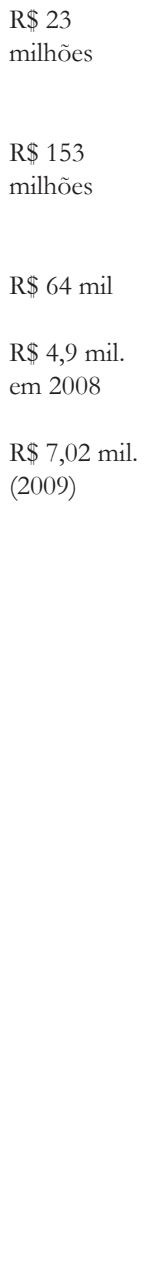 & $\begin{array}{l}\text { Municípios } \\
\text { Famílias } \\
\text { Famílias } \\
\text { Cidadãos/ } \\
\text { famílias } \\
\text { cidadãos } \\
\text { Famílias/ } \\
\text { Agriculto- } \\
\text { res } \\
\text { Agriculto- } \\
\text { res }\end{array}$ & $\begin{array}{l}\text { Regulatória } \\
\text { Regulatória } \\
\text { Regulatória } \\
\text { Regulatória } \\
\text { Regulatória } \\
\text { Regulatória } \\
\text { Regulatória }\end{array}$ \\
\hline
\end{tabular}




\begin{tabular}{|c|c|c|c|c|}
\hline \multirow[t]{2}{*}{$\begin{array}{l}\text { "Operação Ci- } \\
\text { dadania Xingu" }\end{array}$} & $\begin{array}{l}\text { Cursos de: cooperativismo, produção sustentá- } \\
\text { vel; sistemas agroflorestais; aquicultura e pesca } \\
\text { (técnicos Embrapa). } \\
\text { - Regularização fundiária e acompanhamento } \\
\text { técnico de } 15 \text { módulos ocupados por agricul- } \\
\text { tores familiares } \\
\text { - Realização de consultas médicas com remé- } \\
\text { dios para famílias carentes (103,2 mil atendi- } \\
\text { mentos) } \\
\text { - Dezembro, 2011. Discurssão entre gestores } \\
\text { do Sistema Único de Saúde (SUS) e represen- } \\
\text { tantes dos movimentos sociais sobre o cres- } \\
\text { cimento da população como consequência } \\
\text { da chegada de mil trabalhadores. Propõe-se a } \\
\text { criação do Centro de Referência em Saúde do } \\
\text { Trabalhador (Cerest) e a ampliação das Redes } \\
\text { Prioritárias de Atenção à Saúde. }\end{array}$ & $\begin{array}{l}\text { inversão } \\
\text { de RS } 1.5 \\
\text { milhões }\end{array}$ & $\begin{array}{l}\text { jovens } \\
\text { agricultores } \\
\text { agricultores } \\
\text { cidadãos }\end{array}$ & regulatória \\
\hline & $\begin{array}{l}\text { Início obras: } 2013 . \\
\text { Total: }\end{array}$ & $\begin{array}{l}\mathrm{R} \$ 270 \\
\text { milhões }\end{array}$ & & \\
\hline
\end{tabular}

Fontes:

(1) Informações da Secom. Disponível em: http://blog.planalto.gov.br/arco-verde-e-arco-defogo-serao-intensificadas-em-decorrencia-de-conflitos-na-amazonia/>;

(2) http://www.brasil.gov.br/noticias/arquivos/2011/10/13cidadania-xingu-conclui-operacaocom-mais-de-170-mil-atendimentos-no-norte-do-pais

\subsection{Dinâmicas a partir de 2012}

O ano de 2012 marca o início das obras da UHBM, sendo mostrados claramente os seus primeiros impactos. A observação das dinâmicas políticoadministrativas centra-se na esfera de governo municipal. As eleições municipais do ano de 2012 mostram um descontentamento da população com a atuação do governo do PSDB, na gestão da prefeita Odileida Sampaio (2004-2012). Nas eleições de 2012, PMDB obteve a maioria (41,65\%), sendo eleito Domingos Juvenil prefeito de Altamira. O novo governo deparou-se com importantes desafios herdados da gestão anterior, cujo aspecto central constitui a construção, já iniciada, da UHBM.

O Planejamento urbano. Entendemos por planejamento um sentido amplo que pode ser resumido como a ação humana consciente e que adquire também uma dimensão histórica. Não há uma teoria do planejamento, mas um pensamento crítico-teórico que tem evoluído através do tempo, e que pode ser classificado como correntes ou "escolas". O planejamento fundamentado na perspectiva sistêmica baseia-se em conceitos e categorias como "complexidade", "racionalidade sistêmica" ou "racionalidade das decisões únicas", todas elas influenciadas por Niklas Luhmann. E o planejamento político-administrativo 
baseia-se em uma racionalidade do mesmo processo administrativo que, por sua vez, tem a capacidade de orientação baseada em premissas decisórias, em que o planejamento pode ser definido como a capacidade para dirigir um sistema administrativo a partir de "pautas decisionais".

Nos Planos de Desenvolvimento Sustentável aplicados no estado do Pará, a organização e a pauta têm sido fixadas pelo governo estadual e pela Secretaria de Integração Regional (SEIR) durante o período do governo do Partido dos Trabalhadores (2007-2011). As "pessoas que tomam decisões" com referência às atitudes, motivos, capacidades, contatos e organizações de funcionários, reportam-se à capacidade e competências dos servidores públicos designados para a organização e gestão sob as diretrizes do Estado. O planejamento requer estudos de diagnóstico imprescindíveis para o projeto de planejamento. Embora no governo do PSDB tenha-se tentado estabelecer um planejamento estratégico, na prática houve poucos avanços: "Se não foi nada até hoje questão da viabilidade das ruas, questão das artérias de entrada e saída, todo um planejamento" (Antônio Carlos Bortoli, Secretário de Planejamento 2008-2012/PSDB). A necessidade de criar um centro de planejamento municipal parece prioritária para o atual prefeito do PMDB: “Aqui está acontecendo um pouco menos que lá; lá foi pior ainda que aqui. Tucuruí foi muito pior do que aqui. Itaipu também." (Raineiro Meireles, Secretário de Planejamento de Altamira).

O Plano Diretor (PD) é um instrumento básico de planejamento municipal para nortear a implantação de políticas de desenvolvimento urbano, direcionando a ação dos agentes públicos e privados. Para que o PD seja implantado é necessário que seja formalizado através da aprovação de uma lei do Plano Diretor na Câmara Municipal. O PD deve explicitar os objetivos para o desenvolvimento urbano do município, com base nas perguntas: "o que eu quero?” ou “o que nós queremos neste município?”. Os objetivos não são “dados", ou seja, não estão definidos a priori, visto que é necessário que sejam discutidos democraticamente e consensualizados de alguma maneira com a sociedade civil do município. O PDA foi financiado pela Eletronorte e realizado pela empresa consultora Tecnus, de Brasília, contratada pela Eletronorte. Esta empresa contratou técnicos e especialistas alheios à realidade de Altamira: "Era um pessoal muito bom, mas que deveria ter se fixado aqui. Ter, inicialmente, treinado uma equipe multidisciplinar. Eles poderiam ter feito uma parceria com a Universidade" (Antônio Carlos Bortoli, Secretário de Planejamento de Altamira, PSDB). Sem dúvida, as mudanças técnicas introduzidas na construção da UHBM provocaram o aumento da quota do nível das águas. Este fato significou que as previsões de inundação de bairros de Altamira deveriam ser modificadas, com 
as seguintes mudanças no PD: "Nós temos que atualizar agora o zoneamento, porque uma grande parte do PDA foi feita em cima do nosso Plano (aprovado em 6 de dezembro de 2010)" (Antônio Carlos Bortoli, Secretário de Planejamento de Altamira, PSDB). Devido a este fato e à falta de dados confiáveis em sua concepção, surgiram diversas falhas em sua concepção: "Foi tecnicamente bem feito, mas mal feito no conceito de se fazer" (Antônio Carlos Bortoli, Secretário de Planejamento de Altamira, PSDB).

O Plano Plurianual4 (PPA) é um plano de médio prazo que estabelece as diretrizes, os objetivos e as metas que devem ser seguidas pelo governo municipal, por um período de quatro anos. Referente à questão da participação da cidadania, surgem as críticas feitas pelo atual vice-prefeito: "Não, não foi participativo, eles elaboraram e fizeram" (Joel Mendes, Vice-Prefeito). As críticas provêm também do setor empresarial madeireiro: "na gestão passada, nós sequer fomos consultados para o aproveitamento dessa madeira, e aqui o setor florestal na região tem sete anos que está parado”.

Contudo, aparecem problemas derivados da financiadora do Plano, como a transferência de responsabilidades para o setor privado, para a empresa construtora da UHBM: "se você for ver lá no PPA do estado, você vai ver que não tem nenhum centavo pra cá. $O$ estado transferiu a responsabilidade para a Norte Energia -, é um absurdo. Esta é a situação que está hoje. O governo federal não repassa recursos específicos para o que está acontecendo" (Joel Mendes, Vice-Prefeito 2013).

No documento Licenciamento Ambiental", Plano on Projeto Básico Ambiental (PBA) "constam o detalhamento de todas as medidas mitigadoras e compensatórias e os programas ambientais propostos no EIA/RIMA, que compõem o processo de Licença de Instalação (LI) do empreendimento. O Plano Básico Ambiental destina-se a orientar e especificar as ações e obras que devem ser deflagradas e realizadas para recuperação do passivo ambiental de empreendimentos/atividades efetivas e/ou potencialmente impactantes ${ }^{26}$. Conceitua-se passivo ambiental como o conjunto de degradações constituído por externalidades geradas pela existência de empreendimentos/atividades sobre terceiros e por terceiros sobre esses últimos. O Plano Básico Ambiental (PBA) deve ser elaborado na etapa da formulação do Projeto Básico, e embasado nas recomendações dos estudos ambientais desenvolvidos na etapa do EIA-RIMA.

24 No Brasil, está previsto no artigo 165 da Constituição Federal e regulamentado pelo Decreto 2.829, de 29 de outubro de 1998.

25 Para maiores informações, ver a dissertação: Fainguelernt (2011).

26 Disponível em: http://creaweb.crea-pr.org.br/IAP/arquivos/PBA_Plano_Basico_Ambiental _Padrao.pdf> 
O PBA define as ações e programas a serem desenvolvidos em todas as etapas do projeto, desde o início das obras até a etapa de operação do empreendimento e do seu monitoramento. O PBA do projeto da UHE Belo Monte é composto por 14 planos, 54 programas e 86 projetos ${ }^{27}$. "É uma obra muito grande, eu não sei..., acabou não se fazendo o PBA, por exemplo, quando eu disse, não se preparou. Por exemplo, nós não temos pessoas, e informação pra trabalhar no atendimento, por exemplo, não foi feito um trabalho" (Antônio Carlos Bortoli, Secretário de Planejamento de Altamira, PSDB). O Plano Regional Sustentável (PDRS) adquire uma dimensão diferenciada, claramente territorial, mais ampla, e foi impulsionado pelo governo. O PDRS, "Ele poderá ser, mas ainda não é, porque o caso da multidisciplinaridade que requer, então você tem que ter várias mentes pensando coisas complexas" (Antônio Carlos Bortoli, Secretário de Planejamento de Altamira, PSDB).

O PD estabelece os princípios e normas, além de apontar orientações para ações concretas com o objetivo de desenvolver o município. As ações podem referir-se desde a construção de uma Unidade de Tratamento de Resíduos Sólidos (UTR) até questões relativas ao tratamento de águas ou construção de conjuntos habitacionais. Todas essas ações devem estar orientadas para uma estratégia ampla, com base nos objetivos estabelecidos e consensuais. No ordenamento territorial, o zoneamento (ordenamento territorial) é necessário para impor normas e restrições à iniciativa privada. Esta ação deve ser acompanhada por ações do Poder Público. "Onde estão as pessoas para definir? Onde está o ordenamento territorial?” (Antônio Carlos Bortoli, Secretário de Planejamento de Altamira, PSDB).

Por último, a partir da lei sobre a obrigação de todos os municípios disporem de um plano de resíduos, a Unidade Tratamento Resíduos (UTR). "foram feitos vários projetos, e a Norte Energia, sempre enrolando, comprou outro terreno, por quê? Porque a UTR é um negócio complexo, são várias empresas dentro dela" (Antônio Carlos Bortoli, Secretário de Planejamento de Altamira, PSDB). O mesmo secretário indica: "Eu não sei como é que ficou e a UTR que deveria ser construída no terreno que foi comprado, que foi dado, em função da complexidade, eu tô falando no finalzinho de 2012, e eu conversando, disseram que estava iniciando, mas eu não sei se iniciou ou não, e eu não tive mais a oportunidade".

$\mathrm{O}$ planejamento refere-se ao ordenamento territorial e à requalificação urbana, esta iniciando com o saneamento básico, água, esgoto e drenagem. Em um processo, o início das obras financiadas pela Norte Energia em Altamira ocorreu no ano de 2013.

\footnotetext{
${ }_{27}$ Disponível em: <http://norteenergiasa.com.br/site/2012/05/16/projeto-basico-ambientalda-uhe-belo-monte/ $>$
} 
A tomada de decisão é a ação primordial para o planejamento. A tomada de decisão individual, coletiva e nas organizações é um processo complexo, que está intrinsecamente relacionado a diversas dimensões como a estrutura, a lógica, os processos, os dados e informações, a interação e a comunicação. A teoria da decisão é a teoria sobre as decisões, entendida "como um processo". Com esta proposta, estabelece uma clara diferenciação epistemológica entre decisão e ação e, por sua vez, entre escolha e alternativa. Enquanto as ações têm de ser consideradas como dadas, as decisões, pelo contrário, não têm uma capacidade específica, como seria o caso da ação, mas cujo elemento decisivo constitui a possibilidade de escolha. Não se esclarece necessariamente a alternativa eleita e cada uma precisa de uma decisão, mas deve "ser distinguida" da decisão. Como consequência, as decisões são o "resultado" da tematização da contingência. A decisão, no quadro da contingência, esquece o aspecto subjetivo e reflexivo prévio a toda decisão. "E foram feitas várias audiências públicas, a que toda a população teve acesso, de discutir, de discordar, de concordar, e foram acontecendo as decisões" (Antônio Carlos Bortoli, Secretário de Planejamento de Altamira, PSDB).

O termo "governance" ou governança ${ }^{28}$ refere-se ao conjunto de mecanismos e de procedimentos para tratar com a dimensão plural e participativa da sociedade. Isso implica expandir e aperfeiçoar os meios de interlocução e de administração do jogo de interesses dos diversos atores que conformam a sociedade. Desde o início do projeto, o governo municipal tem o desafio de atuar e posicionar-se estrategicamente contra a empresa construtora Norte Energia e o Consórcio Construtor Belo Monte (CCBM). Trata-se de uma governança marcada por fatos consumados devido às decisões do governo federal sobre a autorização da construção da UHBM. Por parte do governo municipal, tem sido mostrada uma estratégia, reativa pela baixa capacidade de planejamento para um empreendimento de tal envergadura, que contrasta com a expertise do Consórcio construtor nestas situações. Contudo, desde o princípio, a Norte Energia se comprometeu formalmente a realizar uma série de ações e intervenções voltadas ao município, cuja realização ou está atrasada ou não tem sido cumprida:

[...] essa relação com a Norte Energia, por exemplo, das condicionantes montadas eles não estão cumprindo o que foi acordado, eu não tô dizendo que eles não estão fazendo nada, alguma coisa está sendo feita, por exemplo, os postos de saúde (Rainerio Meireles, Secretário de Planejamento de Altamira).

28 Definimos como “a capacidade governamental em sentido amplo, compreendendo a capacidade de ação estatal na implementação de políticas públicas e na implementação das políticas na consecução de metas coletivas" (DINIZ, 1996, p. 22-23). 
[...] mas foram feitas escolas com central de ar e tal, não podemos falar que o consórcio foi totalmente omisso, tá. Poderia ter feito mais, teria que ter sido feito mais." (Rainerio Meireles, Secretário de Planejamento de Altamira)

Como resultado das contínuas interrupções e da falta de compromisso com as promessas feitas pela empresa Norte Energia, o governo municipal do PSDB entrou com uma ação judicial: "é verdade, houve várias cobranças. A prefeita ingressou com uma ação contra a CCBM [...] Não sei se contra o Consórcio Belo Monte ou se foi contra a Norte Energia”.

Desde o início do projeto, o governo municipal encontra-se em uma situação de dissonância política, por não se alinhar com os partidos no poder (2007: PSDB municipal, PT estadual e federal; 2012: PMDB municipal, PSDB estadual e PT federal). Neste descompasso, o governo municipal teve dificuldade de interlocução, como declara o secretário de planejamento: "Eu acho poderia ter tido um apoio maior, uma atenção maior, tanto de estado, quando do governo federal, que é a Norte Energia, hoje está havendo essa deficiência" (Rainerio Meireles, Secretário de Planejamento de Altamira). Nesta declaração, os secretários dos governos municipais (PSDB e PMDB) concordam: "Há duas coisas importantes no município para as quais o Governo Federal é cego, que ele não consegue enxergar. Se não foi nada até hoje a questão da viabilidade das ruas, questão das artérias de entrada e saída, todo um planejamento" (Rainerio Meireles, Secretário de Planejamento de Altamira).

\section{CONCLUSÕES PRELIMINARES}

Como mostram os dados produzidos durante a observação, seria temeroso estabelecer resultados conclusivos, sob o risco de construir subjetivamente uma realidade inexistente. Por isso, limitaremo-nos a oferecer apenas algumas tendências.

A primeira hipótese formulada é confirmada. O PDRS do Xingu é um instrumento para a orientação das políticas públicas e ações, Contudo, muitas dessas políticas apenas constam nas intenções do plano. Os compromissos da Norte Energia têm sido cumpridos apenas em parte. Ações e obras estruturantes como o saneamento da cidade de Altamira foram iniciadas somente no ano de 2013. Como exemplo, a Unidade de Tratamento de Resíduos (UTR) não saiu do papel.

A segunda hipótese também se confirma. A gestão municipal da prefeita Odileia Sampaio e do atual governo de Domingos Juvenil tem estado constantemente em uma posição reativa às decisões políticas governamentais 
tomadas em Brasília ou às decisões econômicas tomadas pela Norte Energia. Este fato se traduz a uma constante adaptação da estrutura administrativa com a criação de organismos, como é o caso da necessidade de uma nova Secretaria e a reconsideração constante do diálogo político com os governos estadual e federal. As decisões têm sido tomadas frequentemente com base em atos consumados, sem o necessário conhecimento de todos os fatores e sem contar com a informação de qualidade elaborada por especialistas. A frágil institucionalidade da região se manifesta também com uma frágil governança, que somente é capaz de se expressar com fortes intervenções na área da segurança pública.

Com base na observação realizada no sistema da administração pública municipal, é possível constatar uma série de processos e tendências:

Observa-se um processo de "morfogênese social", manifestando-se em um processo de diferenciação de estruturas: criação do Conselho Municipal de Meio Ambiente; criação de uma área de planificação; criação de uma equipe multidisciplinar de profissionais para esta área; e participação no Consórcio Belo Monte.

Com relação à planificação, os órgãos do poder municipal e a respectiva administração e gestão pública se depararam com uma situação de fatos consumados, cuja reação na maioria das vezes se deu de forma improvisada. Não dispuseram de dados de qualidade e não controlaram as variáveis necessárias para tomar as decisões no contexto de complexidades em que se encontram.

As políticas públicas implementadas pelo governo federal no âmbito regional e municipal correspondem fundamentalmente a políticas destinadas às famílias, embora de caráter regulatório e não emancipatório ou redistributivo.

\section{REFERÊNCIAS}

AMARAL, F. do. Continuidade e descontinuidade administrativa em governos locais: fatores que sustentam a ação pública ao longo dos anos. 2006. Dissertação (Mestrado) - Escola de Administração de Empresas de São Paulo, São Paulo, 2006.

BAJOIT, G. El cambio social. Análisis sociológico del cambio social y cultural en las sociedades contemporáneas. Madrid: Siglo XXI, 2008.

BRASIL. MinistériodeDesenvolvimento.PlanoTerritorialdeDesenvolvimento Rural Sustentável (PTDRS). Altamira: FVPP-SOMEC, 2010. Disponível em: <http://sit.mda.gov.br/download/ptdrs/ptdrs_qua_territorio095.pdf>. Acesso: 20 jan. 2013. 
CASTRO, E. Resistência dos atingidos pela barragem de Tucuruí e construção de identidade. Cadernos NAEA, v. 10, p. 41-70, 1989.

CGDEX-Comitê Gestor do PDRS do Xingu. Plano de Desenvolvimento Regional Sustentável do Xingu. Belém: CGDEX, 2011.

COSTA, F; CASTANHAR, J. C. Avaliação de programas públicos: desafios conceituais e metodológicos. Revista Administração Pública, set./out., p. 969992, 2003.

DINIZ, E. Governabilidade, governance e reforma do Estado: considerações sobre o novo paradigma. Revista de Serviço Público, Brasília, ano 47, v. 120, n. 2, maio/ago., p. 22-23, 1996.

DYE, T.. Mapeamento dos modelos de análise de políticas públicas. In: HEIDEMAnN, F.; SLAM, J. F. Políticas Públicas e Desenvolvimento. Brasília: Universidade de Brasília, 2009. p. 99-129.

EISENSTADT, S. N. Estudios de modernización y teoría sociológica. In: CARNERO, T. (Ed.). Modernización, desarrollo político y cambio social. Madrid: Alianza, 1992. p. 5-71.

FAINGUELERNT, M. Meandros do discurso ambiental na Amazônia: uma análise crítica do processo de licenciamento ambiental da Usina Hidrelétrica de Belo Monte. Niterói: UFF/Instituto de Geociência, 2011.

FEARNSIDE, P. M. Brazil's Balbina Dam: Environment versus the legacy of the pharaohs in Amazonia. Environmental Management, v. 13, n. 4, p. 401-423, 1989.

FEARNSIDE, P. M. The evolving context of Brazil's environmental policies in Amazonia. NAEA/UFPA. Novos Cadernos NAEA. v. 16, n. 2, p. 9-25, dez. 2013.

FEHR, H. Probleme der Gründung politische Institutionen in Ost-Mitteleuropa. In: GÖHLER, Gerhart (Hrsg.). Die Eigenart der Institutionen. [s.l.]: BadenBaden, 1994. p. 331-349.

FILHO, O. S. (Org.). Tenotâ-mô. Alertas sobre as consequências dos projetos hidrelétricos no rio Xingu. International Rivers Network, 2005. Disponível em: <http://www.socioambiental.org/banco_imagens/pdfs/tenotamo.pdf >. Acesso em: 24 out. 2014.

GÖHLER, G. (Hrsg.). Institutionswandel. Leviathan, Sonderheft, n. 19, p. 2156, 1996. 
HABERMAS, J. Theorie des Kommunikativen Handelns. Frankfurt a.M.: Suhrkamp, 1981.

HAESBAERT, R.. Região e regionalização num mundo des-territorializado. In: FELDMAN, S.; FERNANDES, A. (org.). O urbano e o regional no Brasil contemporâneo: mutações, tensões, desafios. Salvador: EDUFBA, 2007. p. 3758.

KOLLMORGEN, R. Analytische Perspectiven, soziologische Paradigmata und Theorien sozialen Wandels. Eine metatheoretische Skizze. Otto-von-GuerikeUniversität. Arbeitsbericht, n. 21. Oktober, 2003.

LENSKI, G. History a Social Change. American Journal of Sociology, v. LXXXII, n. 3, p. 548-564, 1976.

LUHMANN, N. Organization und Entscheidung. Opladen. Westdeutscher: Verlag, 1978.

LUHMANN, N. Soziale Systeme. Grundriss einer allgemeinen Theorie. Frankfurt a.M.: Suhrkamp, 1984.

MAGALHÃES, S. M.; HERNANDEZ, F. del M. (Org.). Painel de especialistas. Análise Crítica do Estudo de Impacto Ambiental do Aproveitamento Hidrelétrico de Belo Monte. Belém, 29 out. 2009.

MDTX. SOS Xingu. Um chamamento ao bom senso contra o represamento de rios na Amazônia. Altamira: MDST, 25.07.2001. Disponível em: < http:// www.mabnacional.org.br/site/index.html> Acesso em: 3. fev. 2011.

MENY, Y.; THOENIG, J.-C.. Las políticas públicas. Barcelona: Ariel, 1992.

MERKEL, W. Theorien der Transformation: Die demokratische Konsolidierung postautoritärer Gesellschaften. In: BEYME, Klaus von; OFFE, Claus (Hrsg.). Politische Theorien in der Ära der Transformation. Politischen Vierteljahresschrift, Sonderheft. n. 26, Opladen, p. 30-58, 1996.

MINISTÉRIO PÚBLICO FEDERAL. Referência: ICP 1.23.003.000063/2007. Disponível em: <63.http://www.prpa.mpf.mp.br/news/2012/arquivos/ ACP $\% 20 \operatorname{Cota} \% 20100 . p d f>$

MIRANDA, A. Políticas e planejamento de sistemas de informação no Brasil: um caminho tortuoso. In: ENCONTRO NACIONAL DA CIÊNCIA DA INFORMAÇÃO, 4. 2004, Salvador Anais... Salvador, 2004. 
NAVARRO, P. Hacia una teoría de la morfogénesis social. Ponencia presentada en los II ENCUENTROS DE TEORÍA SOCIOLÓGICA, 2 "Los límites de la teoría ante la complejidad social”, 1995. Bilbao. Annales... Bilbao, 1995. Disponível em: <http://home.dsoc.uevora.pt/ eje/morfogenesis_social.html> Acceso em: 12 ago. 2012.

NETO, A. Lopes. Lições das Políticas de Desenvolvimento Regional do Brasil. Fortaleza: ABC, 2002.

NOLL, R. G. (Org.). Regulatory policy and the Social Sciences. Berkeley: University of California Press, 1985. p. 67-105.

PINTO, L. F. O custo ecológico das hidrelétricas. In: MAGALHÃES, S.; BRITO, R. C.; CASTRO, E. (Org.). Energia na Amazônia. Belém: UFPA; Museu Emílio Goeldi, 1996. 2.v.

PRATES, A. Administração Federal. Revista do Ministério do Planejamento, Orçamento e Gestão n. 2, p. 1-21., jul./ago.., 1099.

SCHNEIDER, A. L. Pequisa avaliativa e melhoria da decisão política: evolução histórica e guia prático. In: HEIDEMANN, F.; SLAM, J. F. Políticas Públicas e Desenvolvimento. Brasilia: UnB, 2009. p. 311-327.

SECCHI, L. Políticas Públicas: conceitos, esquemas de análise, casos práticos. São Paulo: Cengace Learning, 2010.

SFEZ, L. Crítica de la decisión. México: Fondo Cultura Económica, 1984.

STAHEL, A.; GARRETA, J. C. Desenvolvimento sustentável: ¿sabemos de qué estamos hablando? Algunos criterios para un uso consistente del término sostenibilidad aplicado al desarrollo a partir de una perspectiva sistémica. Revista Internacional de Sostenibilidad, Tecnología y Humanismo, n. 7, p. 39-57, 2011.

SZTOMPKA, P. Sociología del cambio social. Madrid: Alianza, 1995.

TORRES, P. M. La política de las políticas públicas: propuesta teórica y metodología para el estudio de políticas públicas en países de frágil institucionalidad n. 93. Santiago: Cepal, 2004.

TREVISAN, A.; VAN BELLEN, H. Avaliação de políticas públicas: uma revisão teórica de um campo em construção. Revista Administração Pública, maio/ jun., p. 529-550, 2008. 
ULTRAMARI, C.; REZENDE, D. Planejamento Estratégico e Planos Diretores Municipais: Referenciais e Bases de Aplicação. Revista Administração Contemporânea, Curitiba, v. 12, n. 3, p. 717-739, jul./set., 2008.

VIDAL, J. P. A dialética entre o "sistema" e o "mundo de vida" na biogeografia urbana. Novos Cadernos NAEA, v. 12, n. 2, p. 217-240, dez. 2009.

VIDAL, J. P. Collective action and Hydroelectric Plant of Belo Monte (Brazil). An observation based on Strategic Action Fields. Asian Journal Humanities and Social Sciences, v. 1, n. 3, Aug., 2013. Disponível em: <http://www. ajouronline.com/index.php?journal=AJHSS > . Acesso em: 16 nov. 2013.

VIDAL, J. P. Institucionalismo e desenvolvimento na Amazônia. Conflito social na Região do Xingu. Paper do NAEA, n. 230, 2009.

VIDAL, J. P. Institucionalismo y desarrollo sostenible en la Amazonia. La Central Hidroeléctrica en el Río Xingu. Revista Internacional de Sostenibilidad, Tecnología y Humanismo, Catalunya, n. 5, 2010. Disponível em: <http:// upcommons.upc.edu/revistes/handle/2099/14386>. Acesso em: 23 mar. 2011.

VIDAL, J. P.; ROSA FILHO, D. de S. Desafios de uma nova gestão púbica para o Desenvolvimento dos Municípios no Pará. Novos Cadernos Naea, v. 14, n. 2, p. 171-196, dez. 2011. 